\title{
Stage IA Gestational Trophoblastic Tumor AJCC v7
}

National Cancer Institute

\section{Source}

National Cancer Institute. Stage IA Gestational Trophoblastic Tumor A/CC V7. NCI

Thesaurus. Code C87151.

Stage IA includes: T1, M0, Risk factors: low risk. T1: T umor confined to uterus. M0: No distant metastasis. (AJCC 7th ed.) 